\title{
Psychological morbidity in interstitial lung disease: a study from India
}

\author{
Akhlesh Rajpoot ${ }^{1}$, Kranti Garg ${ }^{2}$, Varinder Saini ${ }^{1}$, Nitin Gupta ${ }^{3}$ \\ ${ }^{1}$ Department of Pulmonary Medicine, Government Medical College and Hospital, Chandigarh; ${ }^{2}$ Department of \\ Pulmonary Medicine, Government Medical College, Patiala; ${ }^{3}$ Department of Psychiatry, Government Medical College \\ and Hospital, Chandigarh, India
}

\begin{abstract}
Evaluation of mental health in chronic lung diseases like interstitial lung disease (ILD) and chronic obstructive pulmonary disease (COPD) has always been neglected and underrated. The aim of the study was to determine the psychological morbidity in patients of ILD and to determine its various socio-clinical and psychological correlates. A cross-sectional clinic based descriptive study with 50 ILD patients, 30 COPD patients and 30 healthy controls was undertaken. Psychological distress was assessed using different psychological scales, like General Health Questionnaire-12 (GHQ-12), Patient Distress Thermometer (PDT), Coping Strategy Checklist (CSCL), WHO Quality of Life-
\end{abstract}

Correspondence: Kranti Garg, Department of Pulmonary Medicine, Government Medical College, Patiala, India.

Tel. +91.9646121601, +91.9914433515.

E-mail: drkrantigarg@yahoo.com

Key words: COPD; ILD; GHQ-12; psychological distress.

Contributions: AR, KR, VS, NG, concepts, definition of intellectual content, literature search, clinical studies, experimental studies, data analysis, manuscript preparation, manuscript editing, manuscript review; AR, KR, data acquisition, statistical analysis.

Conflicts of interest: The authors declare no conflict of interest.

Ethics approval and consent to participate: The study was approved by the Institute's Research and Ethics Committee. Consent to participate was obtained.

Patient consent for publication: Not applicable.

Availability of data and materials: The datasets used and/or analyzed during the current study are available from the corresponding author on reasonable request.

Received for publication: 5 June 2020 .

Accepted for publication: 1 September 2020.

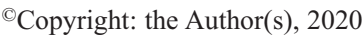

Licensee PAGEPress, Italy

Monaldi Archives for Chest Disease 2020; 90:1434

doi: 10.4081/monaldi.2020.1434

This article is distributed under the terms of the Creative Commons Attribution Noncommercial License (by-nc 4.0) which permits any noncommercial use, distribution, and reproduction in any medium, provided the original author(s) and source are credited.
Brief-26 (WHOQOL-Bref-26) and Depression Anxiety Stress Scale (DASS). The patients with a GHQ-12 score of $\geq 3$ were considered as experiencing psychological distress and additionally referred to consultant psychiatrist for further detailed evaluation and management. Fifty-eight percent of ILD patients and $60 \%$ of COPD patients experienced psychological distress after screening with GHQ-12; $40 \%$ of all the ILD and COPD patients were ultimately diagnosed with a psychiatric disorder, after evaluation by the psychiatrist. Patients of ILD and COPD had significantly higher scores on GHQ-12, CSCL and DASS, and significantly lower scores on WHOQOL-Bref-26 when compared with healthy controls. However, these scores, including PDT did not differ significantly between ILD and COPD patients. The scores on all these scales in the patients of ILD and COPD who were experiencing psychological distress (GHQ $\geq 3$ ) were significantly poorer than those without psychological distress $(\mathrm{GHQ}<3)$. GHQ-12 emerged as an excellent predictor of psychological morbidity. Various other psychological scales correlated with GHQ-12 and amongst each other in both the groups experiencing psychological distress. GHQ-12 and other different scales also significantly correlated with the different clinical indicators in ILD as well as COPD patients having psychological distress. Psychological distress and poorer quality of life was present in a significant percentage of ILD patients, and was comparable to that seen in COPD. Mental health evaluation should be incorporated in the routine management of these patients. Simple, easy and brief screening tools like GHQ-12 can be of immense help.

\section{Introduction}

Interstitial lung disease (ILD) is an umbrella term used for a group of diverse pulmonary conditions, that result in progressive scarring and fibrosis of the lung parenchyma [1]. It is associated with distressing dyspnea, cough, progressive deterioration in exercise tolerance and reduced life expectancy [2]. Both clinicians and patients who are confronted with ILD are frustrated as most of the times there is no cause or cure, and treatment options are very limited. Nevertheless, many patients are successful in making adjustments imposed upon them by their illness. Still, there are instances where patients expect cure and are unable to cope and adjust with the illness, henceforth landing into psychological problems [3].

Psychiatric co-morbidity associated with a physical illness has often been overlooked and remained a low priority in most of the countries [4]. Some studies have reported high prevalence of mental illnesses in patients with chronic respiratory disorders such as asthma, chronic obstructive pulmonary disease (COPD) and allergic rhinitis in the western world $[5,6]$. Psychiatric illnesses associated with ILD are an important group of co-mor- 
bidities but little is known about them. Most of the literature focuses predominantly on depression and anxiety [7]. Various psychiatric co-morbidities, if present, have a significant impact on survival and quality of life, hence need to be identified early and managed optimally [8]. Evidence also suggests that outcome of underlying medical illness improves if co-morbid psychiatric illness is effectively treated. Hence, dealing with mental health issues should routinely be a part of rehabilitation programs for chronic respiratory disorders $[9,10]$.

Indian data on the association of psychological disturbances in ILD are very scarce. Hence this study was planned with the following objectives: i) to determine the psychological morbidity in patients with ILD, and ii) to determine the various socio-clinical and psychological correlates of psychological morbidity in these patients.

\section{Materials and Methods}

\section{Setting}

A cross sectional clinic based descriptive study was done in the Department of Pulmonary Medicine in collaboration with the Department of Psychiatry at Government Medical College and Hospital, Chandigarh, from January 2018 to September 2019.

\section{Sample}

After informed consent, a total of 110 patients were enrolled. The sample comprised 3 groups: i) The case group comprised of 50 patients suffering from ILD. The diagnosis of ILD was made by using multidisciplinary approach with the reconciliation of clinical, radiological (HRCT) and histo-pathological information wherever required [11,12]; ii) the comparison group comprised 30 patients of COPD. COPD was diagnosed as per the diagnostic criteria of the Global initiative for chronic obstructive lung disease (GOLD) [13]; iii) the control group included 30 healthy individuals not suffering from any major medical/ surgical illness and having General Health Questionnaire-12-Hindi version (GHQ-12) score (GHQ-12) $<3$, thus excluding psychological morbidity (defined subsequently).

\section{Exclusion criteria}

Patients were excluded if they were less than 18 years of age, refused consent, had a lack of competency in completing the questionnaires, had psychiatric illness prior to the diagnosis of ILD/COPD, had evident memory deficits on clinical assessment, had organicity (delirium, dementia, etc.) or malignancy or were critically ill.

\footnotetext{
Assessment

A cross sectional assessment of clinical profile, psychosocial and psychiatric aspects was made using the following instruments: i) Socio-demographic and Clinical proforma: A structured proforma was used to record the relevant socio-demographic data, history and clinical details. Spirometry, 6 minute walk distance (6MWD), arterial blood gas analysis (ABG) and other investigations done as per need were also noted. ii) GHQ-12: A 12-item screening instrument commonly used for measuring psychological distress and is validated in the Indian population. Any participant scoring $\geq 3$ was defined as a case with psychological morbidity [14-17]. iii) Patient Distress Thermometer (PDT): A modified visual analogue scale that resembles a thermometer, ranges from 0 to 10 , and is
}

used to assess patients for distress [18]. iv) Coping Strategy Checklist-Hindi version (CSCL): A self-administered scale, comprising of 36 coping strategies used to deal with stressful situations and indicates their use in day to day life $[19,20]$. v) WHO-Quality of Life-Brief- Hindi version (WHOQOL-Bref-26): Contains a total of 26 questions and is used to assess quality of life [21]. vi) Depression Anxiety Stress Scales (DASS): measures the degree of depression, anxiety and stress [22].

\section{Procedure}

The socio-demographic and clinical details of the patients of ILD and COPD and healthy controls were noted as per the structured proforma. All the above listed instruments were administered to patients with ILD and comparison group with COPD. Healthy controls also underwent similar assessment on all the above instruments, except PDT. Patients who scored $<3$ on GHQ-12 score were managed as per protocol for the underlying respiratory disease. The patients with a GHQ- 12 score of $\geq 3$ were deemed to be suffering with psychological distress and additionally referred to a Consultant Psychiatrist for further detailed ICD-10 clinical based evaluation and management [23].

The study was approved by the Institute's Research and Ethics Committee.

\section{Statistical analysis}

Data analysis was done using Statistical Package for Social Sciences, version 22.0 (SPSS 22.0) and included frequency tabulation, association of variables based on Chi-square and risk ratio estimates with 95\% Confidence Interval. All quantitative variables were estimated using measures of central location (mean and median) and measures of dispersion (standard deviation). Normality of quantitative data was checked by Kolmogorov Smirnov tests. In normally distributed data, comparisons were made by t-test (for two groups) and One-way ANOVA (for more than two groups). Where data was not normally distributed, continuous variables were compared using Mann-Whitney U test (between two groups) and Kruskal Wallis test (for more than two groups). All statistical tests were two-sided and the level of statistical significance was set at $5 \%(\mathrm{p}<0.05)$. Spearman correlation coefficients were calculated to see relationship between different variables.

\section{Results}

The relationship of the patients of ILD, COPD and healthy controls with various socio-demographic variables is depicted in Table 1. All three groups were matched with respect to age, gender, educational level and employment status at the time of evaluation. 33 patients ( 21 of ILD and 12 of COPD) had GHQ- $12<3$ while 47 patients ( 29 of ILD and 18 of COPD) had GHQ-12 $\geq 3$ and thus were experiencing psychological distress. The patients of ILD and COPD were matched with respect to 6-MWD (which measures exercise capacity and was taken as a representative of functional impairment) and presence of co-morbidities, though significantly different from healthy controls (Table 1).

Of the 29 ILD patients with psychological distress, 20 were diagnosed by the Consultant Psychiatrist with a psychiatric illness (Depressive Episode: 9, Persistent Mood Disorder: 2, Phobic Anxiety Disorder: 2, Other Anxiety Disorder: 2, Adjustment Disorder: 5); the remaining 9 were Nil Psychiatry. Of the 18 COPD patients with psychological distress, 12 had a diagnosis of psychi- 
atric illness (Depressive Episode: 5, Persistent Mood Disorder: 1, Phobic Anxiety Disorder: 4, Adjustment Disorder: 2); the remaining 6 were Nil Psychiatry. The ILD and COPD patients did not differ with respect to the presence of psychological distress or the different psychiatric illnesses so diagnosed though significantly different from healthy controls (Table 1).

The sub groups of patients of ILD and COPD who were experiencing psychological distress were comparable to the subgroups who were not experiencing psychological distress on variables of gender, educational and presence of other medical co-morbidities. However, there were differences with respect to mean age for COPD group and in employment status for both ILD and COPD subgroups ( $\mathrm{p}=0.011,0.022$ and 0.034 respectively).

In patients with ILD, those experiencing psychological distress were found to have more severer dyspnea with longer duration of symptoms, lower level of oxygenation, lower $\mathrm{FVC} \%$ (percentage of Forced Vital Capacity) and shorter 6-MWD. In patients with COPD, those experiencing psychological distress were found to have more severer dyspnea, poorer level of oxygenation, lower $\mathrm{FEV}_{1} \%$ predicted (percentage of forced expiratory volume in one second) and $\mathrm{FEV}_{1} / \mathrm{FVC} \%$ and shorter 6-MWD (Table 2).

The psychological scales, GHQ-12, CSCL, WHOQOL-Bref26 and DASS were compared in ILD patients, COPD patients and healthy control group. Patients of ILD and COPD had significantly higher scores on GHQ-12, CSCL and DASS, and significantly lower scores on WHOQOL-Bref-26 when compared with healthy control group. However, these scores, including PDT did not differ significantly between ILD and COPD patients (Table 3).

Table 1. Socio-clinical and psychological variables in patients (ILD and COPD) and healthy controls.

\begin{tabular}{|c|c|c|c|c|c|}
\hline Characteristics & & ILD $(n=50)$ & COPD $(n=30)$ & Controls $(\mathrm{n}=30)$ & $p^{*}$ \\
\hline Age in years (mean \pm SD) & & $60.54 \pm 8.80$ & $63.03 \pm 6.88$ & $57.67 \pm 9.09$ & 0.051 \\
\hline Gender (n) & $\begin{array}{l}\text { Female } \\
\text { Male }\end{array}$ & $\begin{array}{l}27 \\
23\end{array}$ & $\begin{array}{c}8 \\
22\end{array}$ & $\begin{array}{l}12 \\
18\end{array}$ & 0.054 \\
\hline Education (n) & $\begin{array}{l}\text { Literate } \\
\text { Illiterate }\end{array}$ & $\begin{array}{l}38 \\
12\end{array}$ & $\begin{array}{c}21 \\
9\end{array}$ & 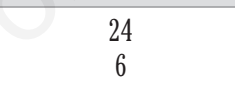 & 0.662 \\
\hline Employment (n) & $\begin{array}{l}\text { Employed } \\
\text { Unemployed }\end{array}$ & $\begin{array}{l}40 \\
10\end{array}$ & $\begin{array}{c}21 \\
9\end{array}$ & $\begin{array}{l}20 \\
10\end{array}$ & 0.368 \\
\hline Co-morbidities & $\begin{array}{l}\text { Present } \\
\text { Absent }\end{array}$ & $\begin{array}{l}36 \\
14\end{array}$ & $\begin{array}{l}11 \\
19\end{array}$ & $\begin{array}{c}0 \\
30\end{array}$ & $0.043^{* *}$ \\
\hline 6 -MWD $(\text { mean } \pm \mathrm{SD})^{\#}$ & & $299.38 \pm 100.11$ & $291.30 \pm 58.86$ & $501.57 \pm 32.72$ & $<0.001^{* *}$ \\
\hline GHQ-12 & $\begin{array}{l}<3 \\
\geq 3\end{array}$ & $\begin{array}{l}21 \\
29\end{array}$ & $\begin{array}{l}12 \\
18\end{array}$ & $\begin{array}{l}30 \\
00\end{array}$ & $<0.001^{* *}$ \\
\hline Psychiatric illness & $\begin{array}{l}\text { Present } \\
\text { Absent }\end{array}$ & $\begin{array}{l}20 \\
30\end{array}$ & $\begin{array}{l}12 \\
18\end{array}$ & $\begin{array}{l}00 \\
30\end{array}$ & $<0.001^{* *}$ \\
\hline
\end{tabular}

ILD, interstitial lung disease; COPD, chronic obstructive lung disease; 6-MWD, 6-minute walk distance; GHQ-12, General Health Questionnaire-12-Hindi version; *Pearson's chi square test, Mann-Whitney U test and ANOVA; ** significant at $\mathrm{p}<0.05 ;$ " ILD vs COPD $=8.080 \pm 17.62 ; \mathrm{p}=0.647 ; \mathrm{ILD}$ s Control $=-202.19 \pm 17.62 ; \mathrm{p}=0.0001^{* *} ;$ COPD s Control $=-210.27 \pm 19.69 ; \mathrm{p}=0.0001^{* *}$.

Table 2. Comparison of various clinical parameters in patients of ILD and COPD with and without psychological distress (GHQ $\geq 3$ and $<3$ ).

\begin{tabular}{|c|c|c|c|c|c|c|}
\hline Variable $($ mean \pm SD) & GHQ $\geq 3$ (n=29 & $\begin{array}{l}=50) \\
H \mathrm{HQ}<3(\mathrm{n}=21)\end{array}$ & p* & $\begin{array}{r}\mathrm{COPL} \\
\mathrm{GHQ} \geq 3(\mathrm{n}=18\end{array}$ & $\begin{array}{l}1=30) \\
H Q<3(n=12)\end{array}$ & $\mathbf{p}^{*}$ \\
\hline mMRC grade & $2.76 \pm 0.64$ & $1.24 \pm 0.83$ & $<0.001^{* *}$ & $2.83 \pm 0.38$ & $1.92 \pm 0.29$ & $<0.001^{* *}$ \\
\hline Duration of symptoms in months & $21.59 \pm 23.14$ & $3.81 \pm 3.83$ & $<0.001^{* *}$ & $33.33 \pm 25.69$ & $15.33 \pm 10.14$ & 0.175 \\
\hline $\mathrm{SpO}_{2}(\%)$ & $93.52 \pm 4.44$ & $96.38 \pm 0.97$ & $0.049 * *$ & $94.33 \pm 3.14$ & $96.92 \pm 0.67$ & $0.005^{* *}$ \\
\hline FEV1 \% predicted & $67.14 \pm 15.86$ & $74.62 \pm 17.0$ & 0.117 & $55.89 \pm 13.75$ & $68.0 \pm 13.11$ & $0.023^{* *}$ \\
\hline FVC \% predicted & $58.83 \pm 13.04$ & $68.62 \pm 16.21$ & $0.022^{* *}$ & $72.72 \pm 14.0$ & $82.0 \pm 12.05$ & 0.071 \\
\hline FEV1/FVC (\%) & $86.56 \pm 6.13$ & $83.86 \pm 9.01$ & 0.153 & $37.41 \pm 27.67$ & $56.78 \pm 19.16$ & $0.044^{* *}$ \\
\hline 6-MWD (meters) & $256.10 \pm 100.84$ & $359.14 \pm 62.04$ & $<0.001^{* *}$ & $258.94 \pm 39.93$ & $342.83 \pm 42.92$ & $<0.001^{* *}$ \\
\hline
\end{tabular}

ILD, interstitial lung disease; COPD, chronic obstructive lung disease; GHQ-12, General Health Questionnaire-12-Hindi version; mMRC, modified Medical Research Council; SpO ${ }_{2}$, Room air saturation; FEV1, forced expiratory volume in 1st second; FVC, Forced vital capacity; 6-MWD, 6-minute walk distance; *Mann-Whitney U test and Student t-test; ** ${ }^{*}$ significant at p<0.05.

Table 3. Psychological scales in patients (ILD and COPD) and healthy controls.

\begin{tabular}{|c|c|c|c|c|c|c|}
\hline Scales (mean \pm SD) & ILD $(n=50)$ & COPD $(n=30)$ & Controls $(\mathrm{n}=30)$ & $\begin{array}{l}\mathrm{p}^{*} \text { (ILD vs } \\
\text { Controls) }\end{array}$ & $\begin{array}{c}\text { p* (COPD vs } \\
\text { Controls) }\end{array}$ & $\begin{array}{l}\mathrm{p}^{*} \text { (ILD } v s \\
\text { COPD) }\end{array}$ \\
\hline GHQ-12 & $3.80 \pm 2.10$ & $3.83 \pm 1.82$ & $0.57 \pm 0.68$ & $<0.001^{* *}$ & $<0.001^{* *}$ & 0.948 \\
\hline PDT & $4.22 \pm 1.91$ & $4.33 \pm 1.56$ & — & - & - & 0.693 \\
\hline CSCL & $12.18 \pm 6.02$ & $13.83 \pm 6.78$ & $3.77 \pm 0.94$ & $<0.001^{* *}$ & $<0.001^{* *}$ & 0.260 \\
\hline WHOQOL-Bref-26 & $270.70 \pm 71.74$ & $261.93 \pm 55.79$ & $386.0 \pm 18.97$ & $<0.001^{* *}$ & $<0.001^{* *}$ & 0.568 \\
\hline DASS & $35.56 \pm 22.50$ & $34.0 \pm 24.44$ & $7.20 \pm 1.71$ & $<0.001^{* *}$ & $<0.001^{* *}$ & 0.720 \\
\hline
\end{tabular}

ILD, interstitial lung disease; COPD, chronic obstructive lung disease; GHQ-12, General Health Questionnaire-12-Hindi version; PDT, patient distress thermometer; CSCL, coping strategy checklist; WHOQOL-Bref26: World Health Organization Quality of Life-Brief-26; DASS, depression anxiety stress scale; *Mann-Whitney U test and Student t-test; **significant at p $<0.05$. 
The ILD patients who were experiencing psychological distress (GHQ $\geq 3$ ) were compared to those who were not experiencing psychological distress (GHQ $<3$ ) on GHQ-12, PDT, CSCL, WHOQOL-Bref-26 and DASS. The scores in the former (i.e. GHQ positive) group were significantly poorer on all these scales. On a similar pattern, the COPD patients who were experiencing psychological distress (GHQ $\geq 3$ ) were compared to those who were not experiencing psychological distress $(\mathrm{GHQ}<3)$; and a similar pattern was observed (Table 4).

An attempt at seeing the various socio-clinical and psychological correlates was attempted in the patients who were experiencing psychological distress amongst both cases (ILD) and comparison (COPD) groups; the results of which are presented in Table 5. As can be seen the various psychological scales correlated with GHQ-12 and amongst each other in both the groups of patients (Table 5).

\section{Discussion}

In our study, the patients of ILD, COPD and healthy controls were matched with respect to age, gender and presence of co-morbidities at the time of evaluation. Our results were similar to studies in the past [24,25]. In principal, functional impairment is prob- ably the main reason because of which patients usually present to the health care facility for seeking treatment. 6-MWD, which measures exercise capacity and is a representative of functional impairment, was hence used to equate the cases (ILD) and the comparison group (COPD) $(\mathrm{p}=0.647)$.

Our study is the first one of its kind to use GHQ-12 as a screening tool to determine psychological distress in patients suffering with ILD. GHQ-12 has been found to be a reliable tool for screening of psychiatric disorders in the past in patients of COPD, tuberculosis and dyspepsia [26,27]. Patients who present with psychological distress, may not always be suffering with an underlying psychiatric illness. These symptoms may exist independently or can be secondary to some physical illness. Hence, the patients with GHQ $\geq 3$, who had psychological distress, were suspected of having a psychiatric co-morbidity and were referred to a psychiatrist for further evaluation and confirmation of diagnosis of a concomitant psychiatric illness.

In our study, 58\% ILD patients and 60\% COPD patients had psychological distress after screening with GHQ-12 by the pulmonologist. Grossly similar, but slight variations in our results from the already available literature could be due to the use of different screening tools (like Global Mental Health Assessment Tool Primary Care Version (GMHAT-PC), Hospital Anxiety and Depression Scale (HADS) and St. George's Respiratory Questionnaire (SGRQ) in different studies [26,28-30].

Table 4. Comparison of various psychological scales in patients of ILD and COPD with and without psychological distress (GHQ $\geq 3$ and $<3)$.

\begin{tabular}{|c|c|c|c|c|c|c|}
\hline \multirow[t]{2}{*}{ Scales (Mean \pm SD) } & \multicolumn{2}{|c|}{ ILD $(n=50)$} & \multirow[t]{2}{*}{$\mathbf{p}^{*}$} & \multicolumn{2}{|c|}{ COPD $(n=30)$} & \multirow[t]{2}{*}{$\mathbf{p}^{*}$} \\
\hline & $\begin{array}{c}\mathrm{GHQ} \geq 3 \\
(\mathrm{n}=29)\end{array}$ & $\begin{array}{r}\mathrm{GHQ}<3 \\
(\mathrm{n}=21)\end{array}$ & & $\begin{array}{r}\mathrm{GHQ} \geq 3 \\
(\mathrm{n}=18)\end{array}$ & $\begin{array}{r}\mathrm{GHQ}<3 \\
(\mathrm{n}=12)\end{array}$ & \\
\hline GHQ-12 & $5.31 \pm 1.39$ & $1.71 \pm 0.46$ & $<0.001^{* *}$ & $5.056 \pm 1.30$ & $2.0 \pm 0.00$ & $<0.001^{* *}$ \\
\hline PDT & $5.55 \pm 1.30$ & $2.38 \pm 0.67$ & $<0.001^{* *}$ & $5.28 \pm 1.27$ & $2.92 \pm 0.51$ & $<0.001^{* *}$ \\
\hline $\mathrm{CSCL}$ & $16.90 \pm 2.69$ & $5.67 \pm 1.35$ & $<0.001^{* *}$ & $18.56 \pm 4.29$ & $6.75 \pm 1.22$ & $<0.001^{* *}$ \\
\hline WHOQOL-Bref-26 & $216.69 \pm 37.80$ & $345.29 \pm 23.22$ & $<0.001^{* *}$ & $221.67 \pm 31.01$ & $322.33 \pm 9.23$ & $<0.001^{* *}$ \\
\hline DASS & $53.45 \pm 9.61$ & $10.86 \pm 2.57$ & $<0.001^{* *}$ & $49.56 \pm 19.36$ & $10.67 \pm 2.46$ & $<0.001^{* *}$ \\
\hline
\end{tabular}

ILD, interstitial lung disease; COPD, chronic obstructive lung disease; GHQ-12, General Health Questionnaire-12-Hindi version; PDT, patient distress thermometer; CSCL, coping strategy checklist; WHOQOL-Bref-26: World Health Organization Quality of Life-Brief-26; DASS, depression anxiety stress scale; *Mann-Whitney U test and Student t-test; ${ }^{* *}$ significant at $\mathrm{p}<0.05$.

Table 5. Correlation of various psychological scales with other variables in patients of ILD and COPD with psychological distress (GHQ-12 $\geq 3$ ).

\begin{tabular}{|c|c|c|c|c|c|c|c|c|c|c|}
\hline Variables & & & LD $(n=29$ & & & & & $\operatorname{PPD}(n=1$ & & \\
\hline & GHQ-12 & PDT & CSCL & $\begin{array}{l}\text { WHOQOL- } \\
\text { Bref-26 }\end{array}$ & DASS & GHQ-12 & PDT & CSCL & $\begin{array}{l}\text { WHOQOL- } \\
\text { Bref-26 }\end{array}$ & DASS \\
\hline Mean age & & & & & & 0.254 & 0.407 & 0.449 & -0.449 & 0.456 \\
\hline Duration of symptoms & s $0.533^{* *}$ & 0.346 & 0.207 & -0.155 & 0.333 & & & & & \\
\hline mMRC grade & $0.694^{* *}$ & $0.643^{* *}$ & $0.632 * *$ & $-0.668 * *$ & $0.656^{* *}$ & $0.490^{*}$ & 0.461 & 0.417 & $-0.480^{*}$ & $0.592 * *$ \\
\hline $\mathrm{SpO}_{2}(\%)$ & $-0.623^{* *}$ & $-0.510 * *$ & $-0.429 *$ & 0.357 & $-0.436^{*}$ & -0.378 & $-0.509 *$ & -0.320 & 0.247 & -0.280 \\
\hline $\mathrm{FEV}_{1} \%$ predicted & & & & & & -0.272 & -0.089 & 0.116 & 0.069 & -0.207 \\
\hline FVC \% predicted & -0.277 & -0.193 & -0.271 & 0.315 & -0.133 & & & & & \\
\hline 6-MWD (meters) & $-0.661^{* *}$ & $-0.697^{* *}$ & $-0.608 * *$ & $0.621^{* *}$ & $-0.664^{* *}$ & -0.078 & -0.025 & -0.111 & 0.108 & -0.304 \\
\hline GHQ-12 & 1 & $0.752^{* *}$ & $0.696^{* *}$ & $-0.567^{* *}$ & $0.660^{* *}$ & 1 & $0.875^{* *}$ & $0.804^{* *}$ & $-0.828 * *$ & $0.895^{* *}$ \\
\hline PDT & $0.752^{* *}$ & 1 & $0.723^{* *}$ & $-0.710^{* *}$ & $0.764^{* *}$ & $0.875^{* *}$ & 1 & $0.745^{* *}$ & $-0.777^{* *}$ & $0.854^{* *}$ \\
\hline CSCL & $0.696^{* *}$ & $0.723^{* *}$ & 1 & $-0.683^{* *}$ & $0.747^{* *}$ & $0.804 * *$ & $0.745^{* *}$ & 1 & $-0.921 * *$ & $0.859^{* *}$ \\
\hline WHOQOL Bref-26 & $-0.567^{* *}$ & $-0.710^{* *}$ & $-0.683^{* *}$ & 1 & $-0.800 * *$ & $-0.828 * *$ & $-0.777^{* *}$ & $-0.921^{* *}$ & 1 & $-0.932 * *$ \\
\hline
\end{tabular}


$40 \%$ of all the ILD (20/50) and COPD (12/30) patients were ultimately diagnosed with a psychiatric disorder, after evaluation by the psychiatrist, results being similar to previous studies [26,28-30]. This striking finding of presence of psychiatric illness in ILD and COPD groups, is probably because both are chronic diseases requiring lifelong treatment. A two-way relationship exists between such chronic respiratory conditions and psychiatric disorders with both exacerbating each other. Patients with advanced lung diseases have difficulty in adjusting to their illness and thus feel low. Vice a versa, psychiatric illnesses impede progress in patient's condition making the ultimate management more and more challenging, and thereby increasing the psychological burden.

When the patients with psychological distress were analyzed for various socio-demographic variables, it was seen that this sub group of patients matched with respect to gender, educational status and presence of other medical co-morbidities. Our results are similar to the already available literature [29,31]. Human psychology involves intertwining of many factors and one factor may supersede the other, making it ineffective. Some psychosocial factors may have a protective role too (e.g., support from family/medical staff, the patients' perception of support, and support from the community, etc.). In a nutshell, actually, there are multiple aspects of the overall environment, which ultimately influence the emotional well-being of patients. However, it seems that suffering from a chronic illness becomes the predominant deciding factor in ultimate psychological well being in such patients, as also seen from our study, and makes other factors like gender, education etc. quite irrelevant.

However, as obvious, psychological distress was found to be significantly associated with unemployment in both ILD and COPD patients, describing an important variable in today's world where cost of treatment in addition to day to day expenditure becomes all the more relevant in influencing the psychological make-up of the patient; especially if he/she is unemployed. The patients of COPD with psychological distress belonged to a higher age group than those without any psychiatric co-morbidity, though there were no such differences in patients of ILD. In ILD, mean duration of symptoms was seen to significantly affect the psychological distress, though a similar phenomenon was not seen in patients of COPD. These findings could be because of the differences in inherent nature, progression over time and resultant debility the two diseases ultimately cause.

Similar to previous studies, our study also showed that except for $\mathrm{FEV}_{1} \%$ predicted and $\mathrm{FEV}_{1} / \mathrm{FVC} \%$, psychological distress had a significant relationship with severity of dyspnea and duration of symptoms, arterial oxygen saturation, FVC, and 6-MWD in ILD patients $[7,31,32]$. The lack of statistically significant correlation of psychological distress with the $\mathrm{FEV}_{1} / \mathrm{FVC} \%$ was because this ratio was either normal or more than normal in ILD patients. In COPD patients, psychological distress was significantly associated with severity of dyspnea, level of oxygenation, $\mathrm{FEV}_{1} \%$ predicted, $\mathrm{FEV}_{1} / \mathrm{FVC} \%$ and 6-MWD. With respect to dyspnea, our results are similar as well as contradictory to the already available literature $[7,33]$. Psychological distress is common in patients suffering from $\mathrm{COPD}$, even when their disease is mild in terms of $\mathrm{FEV}_{1} \%$ predicted and respiratory symptoms, but frequency of psychiatric co-morbidities increases with increasing severity [24]. It was seen that most of our COPD patients were stable with moderate obstruction (GOLD-2). Similar to previous studies available, our study also showed that psychological distress in COPD patients had no significant correlation with the FVC [34].

The present study also compared GHQ-12 with the other scales like PDT, CSCL, WHOQOL-Bref-26 and DASS. ILD and COPD patients with psychological distress had higher scores on GHQ-12,
PDT, CSCL, and DASS, and lower scores onWHOQOL-Bref-26 when compared with patients without psychological distress and healthy controls.

Different studies, as available in the literature, have used different scales for the assessment of psychiatric co-morbidity [29,30,35]. Except for spirometric variables, GHQ-12 correlated with rest of the clinical parameters so studied, in ILD patients with psychological distress. In COPD patients with psychological distress, it correlated with severity of dyspnea only. This could be due to differences in the presentation and course of the two diseases. Other scales so used also correlated to a smaller or larger extent with these clinical indicators except spirometry, in both ILD and COPD patients experiencing psychological distress. Correlation of DASS and WHOQOL-Bref-26 with GHQ-12, as seen in our study, is similar to results of a previous study in COPD patients [36,37]. Our results are also similar to the available studies where DASS was used to find the levels of depression, anxiety and stress in patients of cancer and rheumatoid arthiritis [35,38]. Results of WHOQOL-Bref-26 and their negative correlation with GHQ-12 in our study indicates that greater the psychological distress experienced by patients with ILD and COPD, lower will be their Quality Of Life (QOL). Even though PDT has been approved by the National Comprehensive Cancer Network (NCCN) to measure psychological distress in patients with cancer [39], to the best of our knowledge, the present study is the first one to use PDT and CSCL in patients with ILD and COPD. A significant positive correlation of PDT with GHQ-12 in our study indicates that higher distress levels is positively related with higher levels of psychological distress in these patients with chronic respiratory ailments. Additionally, significant correlation of CSCL with GHQ-12 indicates that though patients with either ILD or COPD are experiencing psychological distress, the greater the distress, higher number of coping strategies will be used by them.

Overall, our results suggest that simple, easy and brief psychological tools such as GHQ-12 and others (CSCL, DASS, WHOQOL-Bref, etc.) can be of immense help as they cannot only be administered in a very short period of time; they can give a basic idea about the psychological status of the patient, avoid unnecessary referrals and thus contribute towards a holistic assessment and management of overall well-being of an individual presenting to a pulmonologist.

\section{Limitations of the study}

It was a cross sectional study with a relatively small sample size. Had it been longitudinal, results at follow up would have contributed further in comparisons. Also, the individuals with a GHQ12 score of $<3$ being without psychological distress were not evaluated any further for psychiatric illnesses, and could have contributed to 'false negatives'. Further studies with a larger sample size are hence needed. Nevertheless, it had its strengths in the groups being matched for certain socio-clinical variables, use of both comparison (COPD) group and a healthy control group, and an in-depth analysis of psychological profile.

\section{Conclusions}

High psychological distress and poorer QOL as noted in patients with ILD suggests that there is a need for mental health 
evaluation for such patients in order to ensure holistic approach to assessment and management using a multidisciplinary approach.

However, rather than entirely depending on a psychiatrist (or a mental health professional), evaluation of psychological distress should be incorporated in the routine management of these patients. Simple tools like GHQ-12, which emerged as an excellent predictor of psychological distress and morbidity in our study, should be used as a quick screen for these patients in busy pulmonology clinics, even in the limited time frames so available.

This approach will be specially relevant in resource-starved and patient-overloaded Low and Middle Income (LAMI) countries like India, where uniform specialist liaison services will continue to remain a dream rather than becoming a reality in the future years to come!

\section{References}

1. Ryerson CJ, Arean PA, Berkeley J, et al. Depression is a common and chronic comorbidity in patients with interstitial lung disease. Respirol 2012;17:525-32.

2. du Bois RM. An earlier and more confident diagnosis of idiopathic pulmonary fibrosis. Eur Respir Rev 2012;21:141-6.

3. Verma S, Cardenas-Garcia J, Mohapatra PR, Talwar A. Depression in pulmonary arterial hypertension and interstitial lung diseases. N Am J Med Sci 2014;6:240-9.

4. Churchill R. No health without mental health: A role for the Cochrane Collaboration. Cochrane Database Syst Rev 2010;2011:ED000012.

5. de Miguel Díez J, Hernández Barrera V, Puente Maestu L, et al. Psychiatric comorbidity in asthma patients. Associated factors. J Asthma 2011;48:253-8.

6. Spitzer C, Gläser S, Grabe HJ, et al. Mental health problems, obstructive lung disease and lung function: findings from the general population. J Psychosom Res 2011;71:174-179. doi:10.1016/j.jpsychores.2011.03.005

7. Ryerson CJ, Berkeley J, Carrieri-Kohlman VL, et al. Depression and functional status are strongly associated with dyspnea in interstitial lung disease. Chest 2011;139:609-16.

8. Kreuter M, Ehlers-Tenenbaum S, Palmowski K, et al. Impact of Comorbidities on Mortality in Patients with Idiopathic Pulmonary Fibrosis. PLoS One 2016;11:e0151425.

9. Stiefel F, Zdrojewski C, Hadj FB, et al. Effects of a multifaceted psychiatric intervention targeted for the complex medically ill: A randomized controlled trial. Psychother Psychosom 2008;77:247-56.

10. Bateman ED, Hurd SS, Barnes PJ, et al. Global strategy for asthma management and prevention: GINA executive summary [published correction appears in Eur Respir J 2018;51]. Eur Respir J 2008;31:143-78.

11. Raghu G, Collard HR, Egan JJ, et al. An official ATS/ERS/ JRS/ALAT statement: idiopathic pulmonary fibrosis: evidence-based guidelines for diagnosis and management. Am J Respir Crit Care Med 2011;183:788-824.

12. Wallis A, Spinks K. The diagnosis and management of interstitial lung diseases. BMJ 2015;350:h2072.

13. Global strategy for the diagnosis, management and prevention of chronic obstructive pulmonary disease 2019 Report. Accessed on 5th June 2020. Available from: https:// goldcopd.org/wp-content/uploads/2018/11/GOLD-2019-v1.7FINAL-14Nov2018-WMS.pdf.
14. Montazeri A, Harirchi AM, Shariati M, et al. The 12-item General Health Questionnaire (GHQ-12): translation and validation study of the Iranian version. Health Qual Life Outcomes 2003;1:66.

15. Gautam S, Nijhawan M, Kamal P. Standardization of Hindi version of Goldberg's General Health Questionnaire. Indian J Psychiatry 1987;29:63-6.

16. Mattoo SK, Handa S, Kaur I, et al. Psychiatric morbidity in vitiligo: prevalence and correlates in India. J Eur Acad Dermatol Venereol 2002;16:573-8.

17. Goldberg DP, Gater R, Sartorius N, et al. The validity of two versions of the GHQ in the WHO study of mental illness in general health care. Psychol Med 1997;27:191-197. doi:10.1017/s0033291796004242.

18. Asberg M, Montgomery SA, Perris C, Schalling D, Sedvall G. A comprehensive psychopathological rating scale. Acta Psychiatr Scand Suppl 1978;271:5-27.

19. Sharma Y, Mattoo KS, Kulhara P, et al. Stres and coping in women with cervical and breast cancer in india. German $\mathrm{J}$ Psychiatry 2003;2:40-8.

20. Cooper CL, Faragher EB. Coping strategies and breast disorders/cancer. Psychol Med 1992;22:447-55.

21. The WHOQOL Group. Development of the World Health Organization WHOQOL-BREF quality of life assessment. Psychol Med 1998;28:551-8.

22. Lovibond SH, Lovibond PF. Manual for the Depression Anxiety Stress Scales. (2nd. Ed.) Sydney: Psychology Foundation of Australia; 1995.

23. World Health Organization. The International Classification of Diseases-10th Revision. Geneva: World Health Organization; 1992.

24. Chaudhary SC, Nanda S, Tripathi A, et al. Prevalence of psychiatric comorbidities in chronic obstructive pulmonary disease patients. Lung India 2016;33:174-8.

25. Tzanakis N, Samiou M, Lambiri I, et al. Evaluation of healthrelated quality-of-life and dyspnea scales in patients with idiopathic pulmonary fibrosis. Correlation with pulmonary function tests. Eur J Intern Med 2005;16:105-12.

26. ydin IO, Uluşahin A. Depression, anxiety comorbidity, and disability in tuberculosis and chronic obstructive pulmonary disease patients: applicability of GHQ-12. Gen Hosp Psychiatry 2001;23:77-83.

27. se AW, Lai LH, Lee CC, et al. Validation of Self-administrated Questionnaire for Psychiatric Disorders in Patients with Functional Dyspepsia. J Neurogastroenterol Motil 2010;16: $52-60$.

28. Sharma BB, Singh S, Sharma VK, et al. Psychiatric morbidity in chronic respiratory disorders in an Indian service using GMHAT/PC. Gen Hosp Psychiatry 2013;35:39-44.

29. Lee YJ, Choi SM, Lee YJ, et al. Clinical impact of depression and anxiety in patients with idiopathic pulmonary fibrosis. PLoS One 2017;12:e0184300.

30. Holland AE, Fiore JF Jr, Bell EC, et al. Dyspnoea and comorbidity contribute to anxiety and depression in interstitial lung disease. Respirol 2014;19:1215-21.

31. Akhtar AA, Ali MA, Smith RP. Depression in patients with idiopathic pulmonary fibrosis.Chron Respir Dis 2013;10:127-33.

32. Youssef HAA, Sabry YY, Sadek MN, et al. Study of the relationship of dyspnea with depression and functional status in patients with interstitial lung disease. Egyptian J Chest Dis Tuberc 2015;64:269-75.

33. Sanchez O, Caumont-Prim A, Gillet-Juvin K, et al. Activityrelated dyspnea is not modified by psychological status in peo- 
ple with COPD, interstitial lung disease or obesity. Respir Physiol Neurobiol 2012;182:18-25.

34. Vögele C, von Leupoldt A. Mental disorders in chronic obstructive pulmonary disease (COPD). Respir Med 2008;102:764-773. doi:10.1016/j.rmed.2007.12.006

35. Covic T, Cumming SR, Pallant JF, et al. Depression and anxiety in patients with rheumatoid arthritis: prevalence rates based on a comparison of the Depression, Anxiety and Stress Scale (DASS) and the hospital, Anxiety and Depression Scale (HADS). BMC Psychiatry 2012;12:6.

36. Yohannes AM, Dryden S, Hanania NA. Validity and
Responsiveness of the Depression Anxiety Stress Scales-21 (DASS-21) in COPD. Chest 2019;155:1166-77.

37. Shavro SA, Ezhilarasu P, Augustine J, et al. Correlation of health-related quality of life with other disease severity indices in Indian chronic obstructive pulmonary disease patients. Int J Chron Obstruct Pulmon Dis 2012;7:291-6.

38. Jain A, Lolak S. Psychiatric aspects of chronic lung disease. Curr Psychiatry Rep 2009;11:219-25.

39. Singh RP, Singh H, Singh CJ, Kaur KT. Screening of Psychological Distress in Cancer Patients During Chemotherapy: A Cross-sectional Study. Indian J Palliat Care 2015;21:305-10. 